\title{
A Mark in Time Saves Nein
}

\author{
Bruce Bueno de Mesquita and A.F.K. Organski
}

\begin{abstract}
A method for predicting political interactions and policy outcomes based on two political theorems is presented and illustrated with an examination of the decision to merge the two German currencies. Political perceptions and actions are anticipated by combining the substantive knowledge of area experts with the theoretical insights embedded in the median voter theorem and a monotonicity theorem that links expectations to probabilistic statements of action. The proposed model has proven accurate about 90 percent of the time.

The proposed forecasting method identifies a sequential strategy that may have been followed by Chancellor Kohl in forging the coalition needed to merge successfully the two German currencies. Using comparative statics, the analysis suggests how subtle and sophisticated Chancellor Kohl had to be to succeed in getting the policy outcome he desired despite stiff opposition.
\end{abstract}

It is apparent that 1990 will be remembered as the time of passage from the old to the new Europe. The speedy, peaceful unification of Germany is perhaps the most remarkable of the massive changes which began with the reversal of Soviet policy toward the Western powers; the emergence of new, friendly relations with the United States; and the liberation of Eastern Europe. Events of the past few years have revolutionized the European political environment. The unification of Germany has transformed power realities and the rules under which Germany and Europe will operate in the foreseeable future. A united Germany appears well on the way to becoming the dominant European country in all of Western Europe, and in parts of Eastern Europe as well, making Germany the cornerstone of the new Western European power structure and the new American interlocutor in Europe.

Two points should be made. First, it should be kept in mind that the West German leadership echelons, with a great deal of popular support, have persisted for almost all the time since World War II to assert the unity of the German nation (Dean, 1989; Schweigler, 1989). In a world in which unification appeared unrealizable, the focus of West German strategy was on minimizing the severity of the division of 
Germany. Ironically, this goal was pursued with policies ranging from accommodation to the division of Germany (e.g., recognition of the GDR) at one end, to the proffering of economic assistance to East Germany on the other.

That this relationship has affected the nature of both the GDR and the FRG should be recognized. Both the FRG and the GDR were the richest and most important members (other than the superpowers themselves) of the two economic and political coalitions that, until quite recently, confronted one another (namely, Comecon and the Warsaw Pact, NATO and the EEC). Their recovery from the ravages of World War II were remarkable. West Germany surpassed France in the production of steel in the early 1950s and competes as an exporter of manufactures with Japan. Both the GDR and the FRG were important sources of manufactures for their allies not only for civilian products but also for defense goods. True, East Germany lagged substantially behind the West German state despite extensive economic aid received through its special relationship with West Germany; however, this appears to have been due, in large part, to economic mismanagement which disrupted the national economy more severely than even the cruelest war.

A second impressive element of the situation in regard to the two Germanies was the unbelievable stability in the fundamental socio-economic processes responsible for the ongoing systemic change. Despite the prospective power explosion due to the fusion of the two Germanys, unification has proceeded unimpeded by significant elements within or outside either Germany. Despite the earthquakes that have shaken the political and economic topography of Germany to its roots over the previous 50 years, the new Germany can be expected to be very roughly where it would have been economically had no war occurred.

Although, as already noted, economic performance in East Germany has been stifled, West Germany's economic system is as strong or even stronger than it was before the war. In 1936 the FRG portion of the Reich economic system produced $\$ 26.8$ billion (or 41 percent of the GNP of the United States, then about $\$ 64.7$ billion); in 1980 the same territory produced 32 percent of the value of the US domestic product in the same year (Kaser, 1989). Furthermore, in 1937 West Germany competed in exports with the United Kingdom, the leading exporter of manufactures of the time; today, West Germany is locked in a close race with Japan, the leading exporter of manufactures in our own epoch.

Those knowing German history may be reminded by today's events of the rise of Prussia as it brought under control the other German states. That takeover was to be punctuated by the rapid, relatively bloodless, seven-week conflict between Prussia and Austria, which the former won easily. It was a signal, and all of Europe knew at the time that a system change had occurred and that the pecking order in Europe had changed (Bueno de Mesquita, 1990b). Perhaps we are witnessing a new, peaceful power transition in Europe (Organski and Kugler, 1980).

This paper addresses one fundamental issue regarding the process of German unification today. It seeks to answer the question of who will pay the bill for the anschluss of East Germany and the Federal Republic. There is and will continue to be a substantial tug of war over the issue of costs. This is a central political and economic question, and economic estimates suggest that West German absorption of the GDR will be very costly. Thus the query as to how much it will cost and how such costs will be distributed is of critical importance.

Related to it is the question of why the parties decide the issues the way they will. The political dynamics should prove crucial, and it should be noted that the decision over costs, though made by the Germans, is one in which actors in and out of the 
two Germanys can be expected to play a role. Moreover, the distribution of the economic burden will result in political gains and losses to German leaders.

This paper addresses the outcomes and political dynamics that lead to the policy choices that our analysis forecasts. The substantive focus of the analysis concerns the conversion of East German marks into West German marks. Of equal importance, however, is our interest in illustrating the application of formal modeling techniques as a practical means of evaluating and predicting policy interactions. In this regard, we focus here on the application of two theorems. Black's (1958) median voter theorem is adapted to predict policy outcomes. A theorem about the monotonicity between certain expectations and the escalation of political disputes (Bueno de Mesquita and Lalman, 1986; Banks, 1990) is used to make predictions about the political ramifications of alternative proposals.

\section{The Model}

We present a general model for forecasting policy choices and the attendant pulls and tugs that accompany political decisions. We begin with two commonly assumed constraints that facilitate prediction and explanation: that issues are unidimensional and that preferences (and associated utilities) for potential outcomes diminish steadily the farther in Euclidean distance a possible outcome is from one's most preferred outcome or ideal point.

The two constraints - single-peaked utility functions and unidimensionality are necessary for the application of the median voter theorem. Black's theorem, it will be recalled, states that the ideal point of the median voter is the Condorcet winner under the constraints we have assumed and with a simple majority required for victory. ${ }^{1}$ Research on spatial models of voting following Black (e.g., Kramer, 1972; Davis, DeGroot, and Hinich, 1974; McKelvey, 1976; Schofield, 1976) shows serious limitations in the applicability of Black's theorem to multidimensional issues. Nevertheless, enough issues appear to remain or collapse into a single dimension so that unidimensionality and single-peakedness need not be viewed as so severe or so simplifying as to render subsequent analysis trivial. In fact, the procedure for making predictions outlined here has been applied to a very broad array of political, social, military, and economic issues involving more than 60 countries. It has been successfully applied to internal policy decisions in nations as diverse as India, Italy, Iran, the Soviet Union, Mexico, China, Saudi Arabia, Canada, the Philippines and the United States and it has also been applied to multilateral international negotiations in such settings as the Organization of Petroleum Exporting Countries (OPEC), the North Atlantic Treaty Organization (NATO), and the Association of South East Asian Nations (ASEAN).

An approach that helps predict the most likely outcome in a policy debate surely is of value, but it is inadequate for understanding the political dynamics that produce a settlement and that avoids or enhances the risks of conflict escalation. This latter concern, however, is addressed by Banks's (1990) theorem, which demonstrates that the probability of confrontational escalation is an increasing function of the expected utility from such a confrontation. As Banks notes with regard to an earlier version of the model discussed here, "This justifies the assumption in the expected utility models of Bueno de Mesquita and Lalman (1986) and Lalman (1988) that a decision maker with a higher expected utility from war will be more likely to go to war; indeed Lemma 1 shows this to be the only assumption consistent with rational behavior in an incomplete information environment" (Banks, 1990: 605). Banks's monotonicity 
theorem highlights an important feature of politics. It tells us that the more one expects to gain from challenging a rival perspective, the more likely one is to undertake the challenge.

Through the use of the monotonicity result and the median voter theorem we suggest a simple model of perceptions and expectations that helps us comprehend the environment within which bargaining takes place and that influences the dangers of escalation. We capitalize on the perceptual features of the proposed model by using comparative statics to describe the process by which negotiations unfold, moving from one set of circumstances (and outcomes) to another and then another.

\section{Predicting Policy Choices}

When issues are unidimensional and preferences are single-peaked there must be a Condorcet winner, an alternative that cannot be beaten by any other alternative in a pairwise election process. Many, perhaps most, political choices, however, do not involve elections in which each voter casts a single vote. Nevertheless, the median voter theorem and Anthony Downs's spatial theory of voting (1957) provide a theoretical foundation from which we can gain assistance in predicting the resolution of multilateral disputes. ${ }^{2}$

Let $N=\{1,2,3, \ldots, n\}$ be the set of actors trying to influence a multilateral negotiation. Let $M=\{1,2,3, \ldots, m\}$ be the set of all issues discussed in a multilateral negotiation and let $R_{m}$ be the real number line segment, bounded for convenience between 0 and 1, that describes the policy continuum for some issue $m$ selected from among the larger set of issues $M$. Let each actor $i, i \in N$, have its own most preferred resolution of issue $m, X_{i}^{*}(m)$, such that on $R_{m}, 0 \leq X_{i}^{*}(m) \leq 1$. For any proposal $X(m) \in R_{m}$, i's utility, $U^{i}$, for $X(m)$ is a monotonically decreasing function of the distance between $X(m)$ and $X_{i}^{*}(m)$, so that $U^{i} X(m)=f\left|X(m)-X_{i}^{*}(m)\right|{ }^{3}$

Each actor $i$ is assumed to be an expected utility maximizer, by which is meant that $i$ calculates the expected value of alternative strategies and pursues the one that he or she believes is in his or her best interest. Of course, that belief may be incorrect.

Of the infinitely many possible proposals, $X(m)$, to resolve issue $m$, how are we to predict which will be chosen? To answer this question, let us first learn a little more about each actor $i$. In this analysis, each actor is endowed with three characteristics. Each actor attaches some utility to each possible outcome $X(m)$ on issue $m$, as already noted. Each participant in the negotiations is also endowed with the power to exert some influence on decisions. Let $C^{i}$ be the capabilities of actor $i$, such that the sum of the capabilities of the participants in a multilateral dispute is 1 , so that $C^{i}$ is actor $i$ 's share of the total influence in the negotiations. Each participant has its own agenda of priorities or salience that it attaches to the issues that must be confronted. Thus, $i$ may attach considerable importance to issue $R_{1}$ and considerably less importance to issue $R_{2}$. Denote the salience of issue $m$ for actor $i$ as $S^{i}(m)$. From the above discussion, then, we see that each actor is described by three values $\left[U^{i} X(m), C^{i}\right.$, $\left.S^{i}(m)\right]$ on each issue.

The insights derived from the median voter theorem can be applied to almost any political setting. Even in authoritarian regimes, the exercise of power may be understood as a form of voting. When alternative courses of action are pitted against each other, the array of forces on either side often determines victory. Of course, this array depends on more than the relative power of the competing interests. It depends also on the willingness to spend influence on the issue in question $\left[S^{i}(m)\right]-$ a budget constraint - and the intensity with which each actor prefers one proposed settlement 
(e.g., $U^{i} X_{j}(m), j$ 's proposal), to another $\left(U^{i} X_{k}(m), k\right.$ 's proposal). Thus, each group has a total number of potential "votes" equal to its capabilities, but discounts those "votes" by its salience for the issue and by how much it prefers the particular options under consideration. The "votes" cast by actor $i$ in a comparison of alternatives $X_{j}(m)$ and $X_{k}(m)$ are said to equal $V_{i}$ where:

$$
\begin{gathered}
V_{i} \text { given }\left[X_{j}(m), X_{k}(m)\right]= \\
C^{i} \times S^{i}(m) \times\left(U^{i}\left[X_{j}(m)\right]-U^{i}\left[X_{k}(m)\right]\right)
\end{gathered}
$$

The sum of "votes" across all actors in a comparison between $X_{j}(m)$ and $X_{k}(m)$ equals $V_{j k}$ where

$$
V_{j k}=\sum_{i=1}^{n} V_{i} \text { given }\left[X_{j}(m), X_{k}(m)\right]
$$

If $V_{j k}$ is greater than zero, then $X_{j}(m)$ defeats $X_{k}(m)$, indicating that the tacit coalition in favor of $j$ 's proposal $X_{j}(m)$ is more motivated and powerful than the coalition supporting $k$ 's proposal, $X_{k}(m)$. If $V_{j k}$ is less than zero, $X_{j}(m)$ is defeated by $X_{k}(m)$ and if $V_{j k}$ equals zero the competing interests are collectively indifferent between the two alternatives.

In any negotiation, there are likely to be many more than two proposed settlements. By pitting all alternatives against one another two at a time, the Condorcet winner is found and is the predicted outcome (Black, 1958). In practice, of course, it is impractical to compare an infinite number of alternatives. But, one can set a sufficiently fine gradient on $R_{m}$ to insure with a very high probability that one has made a prediction that is sufficiently close to the precise contents of a settlement as to be acceptably accurate.

\section{Altering the Expected Outcome: Manipulating Perceptions}

The forecasting element of the model reveals what decision-makers should expect if everyone acts sincerely in accordance with their underlying preferences. What, however, can a decision-maker do if the predicted outcome is not to his or her liking? Is there anything that can be done to improve the expected outcome?

It is possible for actors to cooperate in private, sophisticated deals to rearrange outcomes. The perceptual component of the model guides the analyst's inquiries so as to facilitate understanding which "deals" are feasible and which are not. ${ }^{4}$ If an interest group is dissatisfied with the expected outcome, there are essentially four courses of action by which this group - the focal group - might improve its prospects. The group leadership can:

(1) alter its own level of effort (i.e., change $S^{i}(m)$;

(2) shift its revealed position, selecting $X_{i}(m)$ such that $U^{i} X_{i}^{*}(m) \neq U^{i} X_{i}(m)$;

(3) influence those who are willing to make concessions to the focal group so that those other groups alter their level of effort (i.e., $S^{k}(m)$ ); or

(4) influence those who are willing to make concessions to the focal group so that those other groups alter their revealed position $X_{k}(m)$ so that $U^{k} X_{k}^{*}(m)$ $\neq U^{k} X_{k}(m)$.

Decision-makers interested in ascertaining what leverage they can exert could benefit from estimating the beliefs held by each other actor. To do so requires a focus 
on the three characteristics - $U^{i} X(m), S^{2}(m), C$ - used to estimate each player's expected utility from challenging or not challenging the policy outcome of each potential rival and for approximating the expected utility each actor $i$ believes its rival expects to derive from challenging or not challenging the policy goals of $i$. In the model envisioned here, decision makers are assumed to calculate the expected consequences of challenging and of not challenging alternative proposals. The expected utility for $i$ from not challenging rival $j$ 's position $\left(E^{i} U^{i} X_{j}(m)\right.$ given $\left.\tilde{c}\right)$ is estimated by projecting what the relevant decision maker believes is likely to happen in the absence of the exertion of pressure on a rival to persuade the opponent to alter its behavior. One of three contingencies may arise. First, $i$ may anticipate that with some probability $\left(Q^{i}\right)$ rival $j$ will not alter its current policies over the time period of concern to $i$, and so $i$ will derive whatever utility it receives from the preservation of the status quo $(S Q)$ between itself and $j$, that is $\left[U^{i} S Q_{j}(m)\right]$. Alternatively, $i$ may anticipate that $j$ 's position on the issues will change, in which case there is some chance $(T)$ that, from $i$ 's perspective, the policies of $j$ are anticipated to get better (with $U^{i} B_{j}(m)$ being the associated utility) or to get worse $\left[U^{i} W_{j}(m)\right]$, so that $U^{i} B_{j}(m)$ $>U^{i} S Q_{j}(m)>U^{i} W_{j}(m)$. $i$ 's expected utility if it leaves $j$ 's proposal unchallenged is:

$$
\begin{gathered}
E^{i} U^{i} X_{j}(m) \text { given } \tilde{c}= \\
Q^{i}\left[U^{i} S Q_{j}(m)\right]+\left(1-Q^{i}\right)\left[T^{i} U^{i} B_{j}(m)+(1-T) U^{i} W_{j}(m)\right]
\end{gathered}
$$

When $i$ contemplates challenging $j, i$ presumably takes into account the probability that $j$ does not care enough about issue $m$ to challenge any proposed settlement, including $i$ 's policy preference $\left[\left(1-S^{j}\right)(m)\right]$ or that $j$ will resist $i$ 's proposal, in which case there is some likelihood that $i$ will succeed in its efforts to enforce its wishes on $i,\left(P^{i}\right)$, and some probability that it will fail. Should $i$ succeed, then $i$ will derive the utility associated with convincing $j$ to switch from its current policy stance to that supported by $i$. This is denoted by $U^{i} S(m)$, with $U^{i} S(m)=U^{i}\left[X_{i}(m)-X_{j}(m)\right]$. Should $i$ fail, then it confronts the prospect of having to abandon its objectives in favor of those pursued by $j$, denoted by $U^{i} F(m)=U^{i}\left[X_{j}(m)-X_{i}(m)\right]$. The expected utility for challenging $j$ 's proposed resolution of the multilateral dispute $\left(E^{i} U^{i} X_{j}(m)\right.$ given $\left.c\right)$ is:

$$
\begin{gathered}
E^{i} U^{i} X_{i}(m) \text { given } c= \\
S^{j}(m)\left\{P^{i}\left[U^{i} S(m)\right]+\left(1-P^{i}\right)\left[U^{i} F(m)\right]\right\}+\left[1-S^{j}(m)\right]\left[U^{i} S(m)\right]
\end{gathered}
$$

so that the overall expected utility of $i$ is:

$$
\begin{gathered}
E^{i} U^{i} X_{j}(m)= \\
\left(E^{i} U^{i} X_{j}(m) \text { given } c\right)-\left(E^{i} U^{i} X_{j}(m) \text { given } \tilde{c}\right)
\end{gathered}
$$

If equation (5) is greater than zero, then $i$ believes that challenging $j$ 's position is superior to not challenging. If (5) is less than zero, then not challenging is preferred and $i$ is said to be deterred. If (5) equals zero, then $i$ is indifferent between challenging and not challenging $j$ 's proposed settlement. Since each actor evaluates equation (5) vis-à-vis each other actor, and since the estimates of $P^{i}$ include calculations of how all other parties are expected to respond to a confrontation between a given pair $i$ and $j$, placing each other actor in $i$ 's coalition, $j$ 's coalition, or in a neutral position, the estimation of a complete matrix of expected utilities should capture all possible confrontations, negotiations, and capitulations among all the participants in the relevant political arena. 
The terms in equation (5), with the exception of utility terms, are measured in accordance with detailed procedures described by Bueno de Mesquita and Lalman (1986). ${ }^{5}$ Utilities for specific proposals (e.g., $X_{j}(m) \in R_{m}$ ), based on spatial data depicting the location on $R_{m}$ of each actor's most preferred outcome (i.e., $X_{i}^{*}(m)$ ), are evaluated so that:

$$
U^{i} X_{j}(m)=1-\|\left.\left[X_{i}^{*}(m)-X_{j}(m)\right]\right|^{r i}
$$

with $r i$ estimated as in Bueno de Mesquita (1985) and Morrow (1987). Utilities for the marginal gains $\left[\left(U^{i} S(m)\right.\right.$ and $\left.U^{i} B_{j}(m)\right]$ or losses $\left[U^{i} F(m)\right.$ and $\left.U^{i} W_{j}(m)\right]$ from shifts to alternative proposals are evaluated, using the basic building block just described, in the manner delineated in Bueno de Mesquita and Lalman (1986). Equation (5) is estimated from four perspectives, with relevant superscripts on equation (5) indicating from whose perspective the calculation is being viewed:

(1) i’s expected utility for its proposal vis-à-vis each rival;

(2) i's perception of each $j$ 's expected utility vis-à-vis $i$ 's proposal;

(3) j's expected utility for its proposal vis-à-vis each rival; and

(4) j's perception of each $i$ 's expected utility vis-à-vis $j$ 's proposal.

The expected utility values summarized in (1) and (2) and in (3) and (4) respectively describe each actor's perception of its relationship vis-à-vis each other actor. With Banks's monotonicity of escalation theorem in mind, these relationships can be described in continuous form. According to Banks's theorem, the probability with which an actor anticipates confronting a given rival increases monotonically with its expected utility for challenging the rival's proposal. Using this theorem, we state the following expectations:

$$
\begin{aligned}
\operatorname{Pr}(\text { Confrontation }) & P^{i}(\text { Confrontational }) \times \\
\operatorname{Pr}(i \text { Gains Concessions })= & P^{i}(\text { Confrontational }) \\
& P^{j}(\text { Not Confrontational }) \times \\
\operatorname{Pr}(j \text { Gains Concessions })= & P^{i}(\text { Not Confrontational }) \times \\
& P^{j}(\text { Confrontational }) \\
\operatorname{Pr}(\text { Status Quo }) & P^{i}(\text { Not Confrontational }) \times \\
& P^{j}(\text { Not Confrontational })
\end{aligned}
$$

with $P^{i}$ (Confrontational) $=$ an increasing function of expression (5) calculated in accordance with $i$ 's expectations, while $P^{j}$ (Confrontational) is an increasing function of $j$ 's estimation of its expected utilities. The specific functional relationship assumed here is:

$$
P^{i}(\text { Confrontational })=\left(3+E^{i} U^{i} X_{j}(m)\right) / 6
$$

and

$$
P^{j}(\text { Confrontational })=\left(3+E^{j}\left(U^{j} X_{i}(m)\right) / 6\right.
$$

Of course, the specific functions are ad hoc, but they are consistent with the monotonicity principle implied by Banks (1990) and Bueno de Mesquita and Lalman (1986). By identifying the values of (6) and (7) for each pair of interested actors in a multilateral setting we are able to evaluate all of the interactions that can arise and, thereby, assess the likely conditions under which an issue might be settled. It is important to recall that each pairwise relationship has already taken into account 
all third-party interactions through the calculation of the appropriately discounted effort of each third party for each member of the pair under review.

The likelihood with which confrontation or concessions occur can be easily displayed in a coordinate space. For ease of presentation, we divide such a space into six sectors, with the boundary between each reflecting a fundamental turning point in the probability functions. Figure 1 displays such a coordinate space, along with relevant labels for each of the six sectors, reflecting the general likelihood of alternative outcomes in accordance with Banks's monotonicity theorem. Figures equivalent to this are used throughout this study to summarize relationships among competing interests.

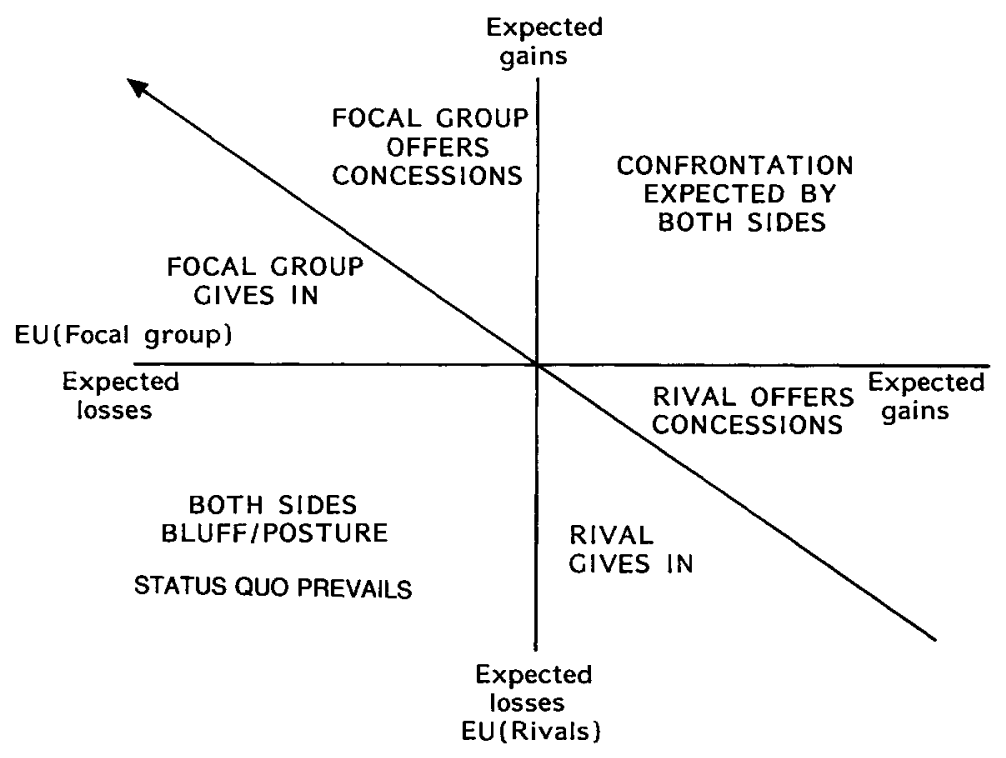

Figure 1. Guide to Graphs.

\section{The Process of Negotiations: Modeling Comparative Statics}

In applying the model it often is of interest to ascertain how strategic maneuvers can shift expected outcomes toward or away from particular results. To the extent that decision makers behave as if they make the calculations described above, the proposed model can be a useful tool, but first it must be sensitized to the strategic efforts to manipulate outcomes that are at the heart of negotiations.

One available strategic modification for an interested party, as noted in the previous section, is to alter its level of effort. Sometimes, by spending more resources and carrying a bigger stick, a group is able to offset its political opposition. By doing so, the group enhances its relative "votes," shifting the expected outcome in the direction it desires. Depending on the particular structure of interests and influence, it is also possible for increased effort to facilitate the formation of a counter-coalition, thereby diminishing the prospects of moving the political settlement in the desired direction. The model presented here allows one to simulate the effects of shifts in level of effort so as to identify the optimal resource expenditure. Furthermore, the model 
reveals cases in which no change in level of effort by the interested group will appreciably affect the predicted outcome. In such cases, other strategies, alone or in combination with this one, may be necessary.

Shifts in policy stances are commonplace during negotiations. Indeed, in some sense this is the essence of bargaining. As interested parties move to more moderate or more extreme positions, they alter the level of support or opposition to their position as they signal others about their flexibility on the issue being negotiated. Sometimes, by moderating a position, a group is able to attract support from significant actors who previously had been in the opposition. Other times, however, moderation fosters outcomes supported by extremists. This can be accomplished by breaking away marginal elements from an opposed coalition, pivoting just enough power in a polarized situation to force a sharp swing toward the opposite extreme and, thereby, maximizing the interested party's expected utility.

It is also true that moves away from moderation and toward more extreme positions can shift outcomes toward the center or away from the center depending upon the particular structure of interests in the political setting. Since that setting is defined by the structure of preferences, capabilities, and salience within the model proposed here, the precise effects of a shift in position can be ascertained through simulation, by moving group positions on the issue continuum utilized by the model and then solving the model under these altered assumptions. Perhaps, such simulations of alternative scenarios can even help forestall the implementation of some sophisticated strategies that backfire in actual practice.

When a single group is unable through its own actions to alter appreciably the expected outcome of a negotiation in the direction it desires, then it may consider the possibility of coordinating with other groups. Obviously, this is more difficult and hence more costly than moves that can be implemented unilaterally. When coalition building is dictated, the model can be especially helpful in providing useful guidance. The perceptual analysis, for instance, reveals which groups believe that they should compromise or grant concessions to which particular other groups, through the evaluation of beliefs about the probability that a given rival is inclined to be confrontational or not. Thus, using the perceptual analysis, any interested group (or an interested analyst) can identify the candidates for strategic encounters. A group leader should, for instance, be most inclined to pressure those who believe they must grant concessions to the group's demands. The larger the probability that a rival will not be confrontational, the lower the costs expected to be associated with extracting gains from the foe, thereby making such an actor an especially attractive candidate for influence attempts. By focusing efforts on groups believed to have a high probability of granting concessions, the interested party can most efficiently organize the coalition - with altered levels of effort and/or revealed policy preferences - that will shift the outcome to be most in line with the organizing group's preferences. Again, simulation facilitates evaluating the impact of alternative coalitions so that the one actually constructed yields the best possible outcome at the lowest political cost.

The techniques just described allow the analyst to use comparative statics to evaluate the impact of alternative strategies. This can be done from the perspective of any interest group or of all groups. What is more, the process can proceed in stages, first identifying the best strategic reaction to the initial, base case, circumstance; then analyzing strategic responses to the initial strategy to alter the base case and so forth. In this way, a "movie" of the unfolding process of negotiations, of moves and countermoves, can be constructed. ${ }^{6}$ If a dominant strategy exists it is likely to be discovered through this iterative process. 


\section{German Monetary Integration ${ }^{7}$}

With the model now delineated, we turn to the politics underlying the integration of the East German mark into the West German economy. It is clear that there are important tensions between the political desire for a smooth transition from two Germanys to one and the widespread interest in ensuring economic stability. Of course, economic stability means quite different things for East Germans, West Germans, other Europeans and the rest of the world economy.

The West German mark is a broadly traded, highly valued currency. The East German mark does not share those characteristics. Consequently, East Germans legitimately fear that economic union could mean that their pensions and savings are at risk of becoming much less valuable. West Germans are legitimately concerned that a generous monetary conversion will precipitate runaway inflation and a severe setback for their economy's competitiveness.

For many Europeans, the unification of the two Germanys is creating a new economic hegemony on the continent. It is not surprising that many members of the European community have expressed reservations regarding German unification. As is evident from our analyses, the European community appears to be amenable to an economic agreement that risks creating significant inflation and economic disruption for Germany. Thus, between the conservative views of German bankers and the unbridled desire to avoid any short-term economic costs for union expressed by the Greens and the East German communists there is a wide gulf. Monetary

Table 1.

\begin{tabular}{|c|c|c|c|c|}
\hline Group & Potential & Power & $\begin{array}{l}\text { Preferred } \\
\text { Outcome }\end{array}$ & Salience \\
\hline \multicolumn{5}{|l|}{ West Germany } \\
\hline $\begin{array}{l}\text { Trade Unions } \\
\text { SPD } \\
\text { CDU (Kohl) } \\
\text { FDP } \\
\text { Employers } \\
\text { Econ Council } \\
\text { Fed Bank } \\
\text { Private Banks } \\
\text { Large Businesses } \\
\text { Greens }\end{array}$ & $\begin{array}{l}20 \\
20 \\
80 \\
60 \\
70 \\
20 \\
80 \\
70 \\
70 \\
10\end{array}$ & $\begin{array}{r}3.1 \\
3.1 \\
12.5 \\
9.4 \\
11.0 \\
3.1 \\
12.5 \\
11.0 \\
11.0 \\
1.6\end{array}$ & $\begin{array}{l}5000 \\
5000 \\
4000 \\
2000 \\
2000 \\
2000 \\
2000 \\
2000 \\
2000 \\
\text { Unlimited }\end{array}$ & $\begin{array}{r}70 \\
60 \\
80 \\
80 \\
80 \\
70 \\
100 \\
100 \\
80 \\
40\end{array}$ \\
\hline \multicolumn{5}{|l|}{ East Germany } \\
\hline $\begin{array}{l}\text { CDU } \\
\text { SPD } \\
\text { PM } \\
\text { PDS }\end{array}$ & $\begin{array}{r}30 \\
17 \\
8 \\
4\end{array}$ & $\begin{array}{r}4.7 \\
2.7 \\
1.3 \\
.6\end{array}$ & $\begin{array}{l}5000 \\
5000 \\
5000 \\
\text { Unlimited }\end{array}$ & $\begin{array}{r}90 \\
100 \\
80 \\
100\end{array}$ \\
\hline \multicolumn{5}{|l|}{ International } \\
\hline $\begin{array}{l}\text { E.C. } \\
\text { USA } \\
\text { USSR }\end{array}$ & $\begin{array}{l}40 \\
20 \\
20\end{array}$ & $\begin{array}{l}6.3 \\
3.1 \\
3.1\end{array}$ & $\begin{array}{l}2000 \\
2000 \\
\text { Unlimited }\end{array}$ & $\begin{array}{l}50 \\
50 \\
50\end{array}$ \\
\hline
\end{tabular}


conversion clearly is a potentially explosive issue. It is the question on which we focus.

Data on group capabilities, preferences, and salience were collected on 13 April, 1990 from Professor Donald Hancock. The data are summarized in Table 1. The issue analyzed here concerns the quantity of private savings that will be convertible at a 1:1 ratio of East German marks to West German marks. The data for this study, in conjunction with the two relevant theorems, provide an interesting perspective on the bargaining process that may have produced the now announced and completed agreement to convert up to 4000 marks per person to West German marks at a 1:1 ratio. As will be evident from our analysis, it appears that this agreement was the product of a sequence of subtle maneuvers by the CDU in each of the two Germanys. Our explanation of the outcome - found to be surprising by most Germany-watchers when it was announced - appears to be consistent with the observed facts. Our explanation also proposes details about the sequence of negotiations which eventually can be evaluated against the discovery of the actual facts surrounding the settlement.

At first blush the data in Table 1 suggest that the monetary integration of the two Germanys is less controversial than generally believed. Although it is true that most East German interests favor a 1:1 conversion on at least 5000 marks of private savings while the bulk of the West German interests want only to offer a 1:1 conversion rate for up to 2000 marks of personal savings, still the overwhelming majority of potential power is apparently opposed to accommodating East German wishes. As Figure 2 reveals, about 70 percent of the potential power and 60 percent of the resources utilized on this issue are coalesced behind a 1:1 conversion of only 2000 marks. It is evident that the base prediction using the median voter outcome ought to have been substantially less than the 4000 mark conversion agreement. How can we explain the apparent discrepancy between the distribution of power and interests, on the one hand, and the outcome on the other?

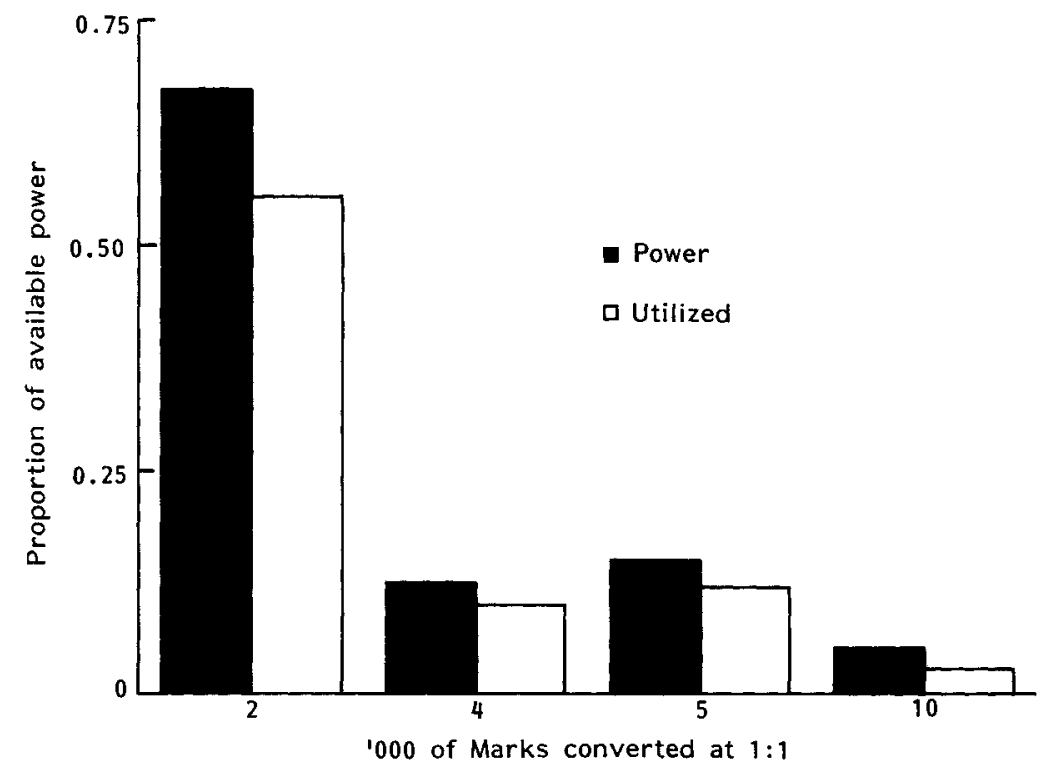

Figure 2. Base Case: Power and Preferences Regarding Mark Conversion. 
The model proposed here draws attention to perceptions as a fundamental aspect of decision making. The case of the union of the two German currencies provides a potent illustration of how beliefs can defeat an outcome that seemingly possesses overwhelming support. Figure 3a depicts Chancellor Kohl's expectations vis-à-vis each of the other groups trying to influence the resolution of this issue, while Figure $3 \mathrm{~b}$ depicts the estimated beliefs of each other group regarding its relationship with Chancellor Kohl's GDU. Figure 3c is the joint effect of the interaction of those two sets of perceptions or what we call "reality".

Of particular interest is the observation that Kohl apparently believed that the Greens in West Germany, the PDS (formerly the Communist Party) in East Germany, the Soviets, the United States, and the European Community would all give in to his wishes on this issue. Figure $3 \mathrm{~b}$ shows that Kohl apparently was correct in thinking that the United States and the European community were inclined to abandon their preference for a 2000 mark conversion arrangement and support Kohl's proposal of 4000 marks. The USSR, on the other hand, is not prepared to capitulate to Kohl's wishes, and is, according to our analysis, not prepared to make concessions to Kohl. We do find, however, that the Soviets were willing to acquiesce to the wishes of the East German CDU in favor of a 5000 mark conversion. Kohl's beliefs about the Greens and the PDS apparently are not correct. The model indicates that they believed Kohl's desires could be blocked and, as implied by Figure 3c, they were unlikely to go along with Kohl's desires.

Figure $3 \mathrm{~b}$ suggests a comparative static analysis in which the United States and the European Community move from 2000 marks on the issue continuum to 4000 marks, in keeping with the analytic result that suggests they would capitulate to Chancellor Kohl on this aspect of economic union. The analysis (from the perspective

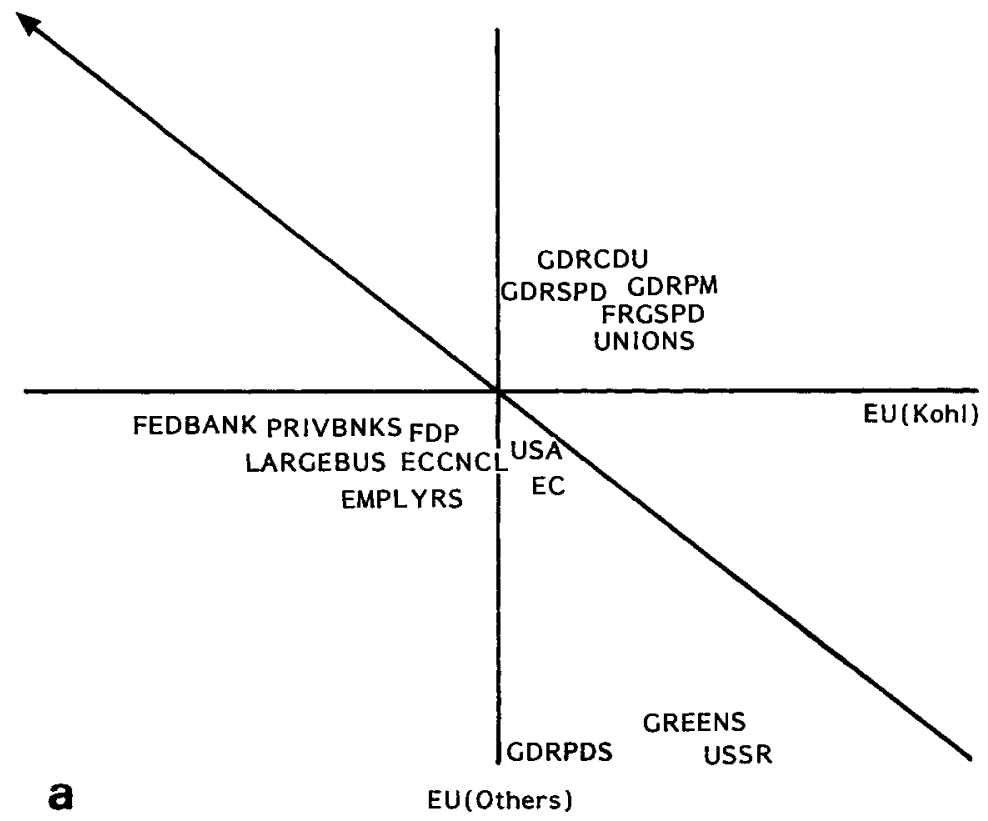

Figure 3a: Kohl's Expectations, Base Case. 


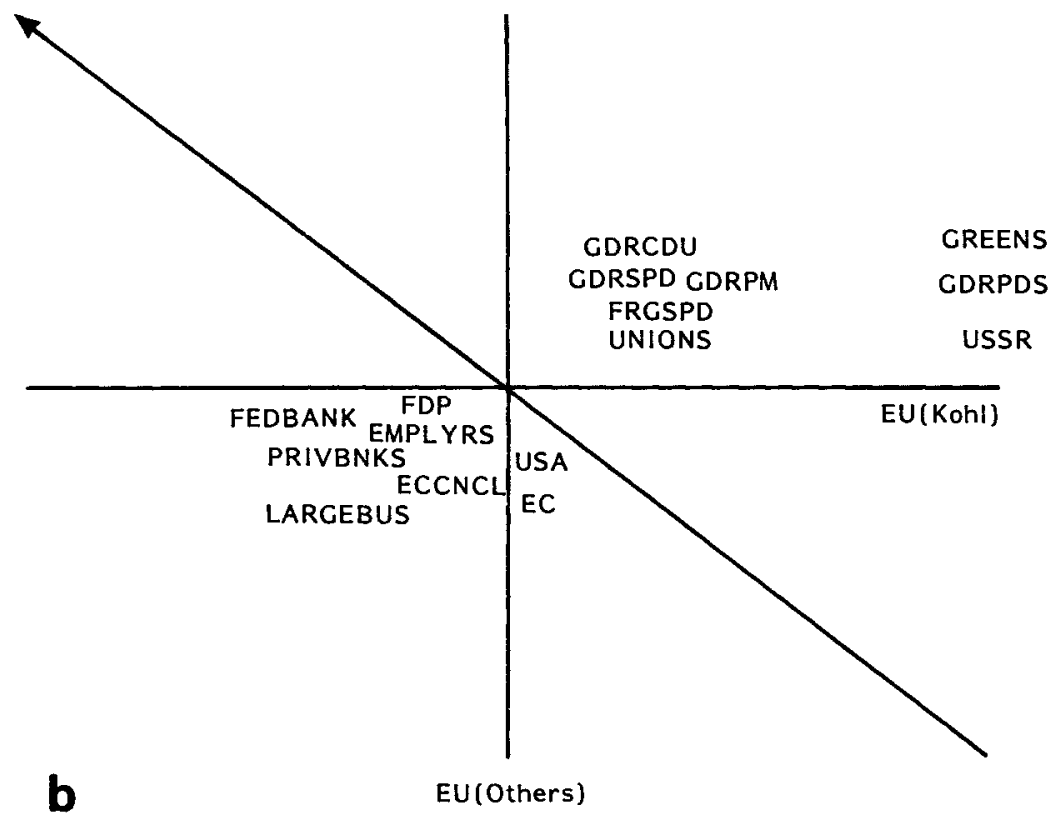

Figure 3b: Expectations vis-à-vis Kohl: Others' Views.

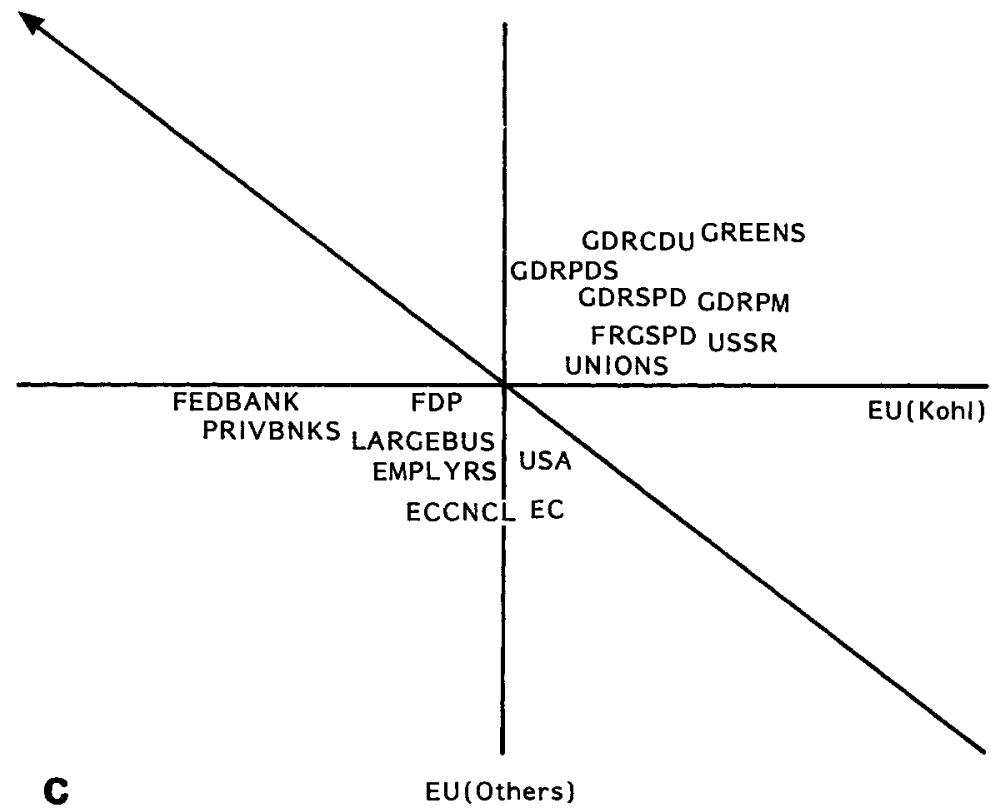

Figure 3c: Base Case Expectations, "Reality" View. 


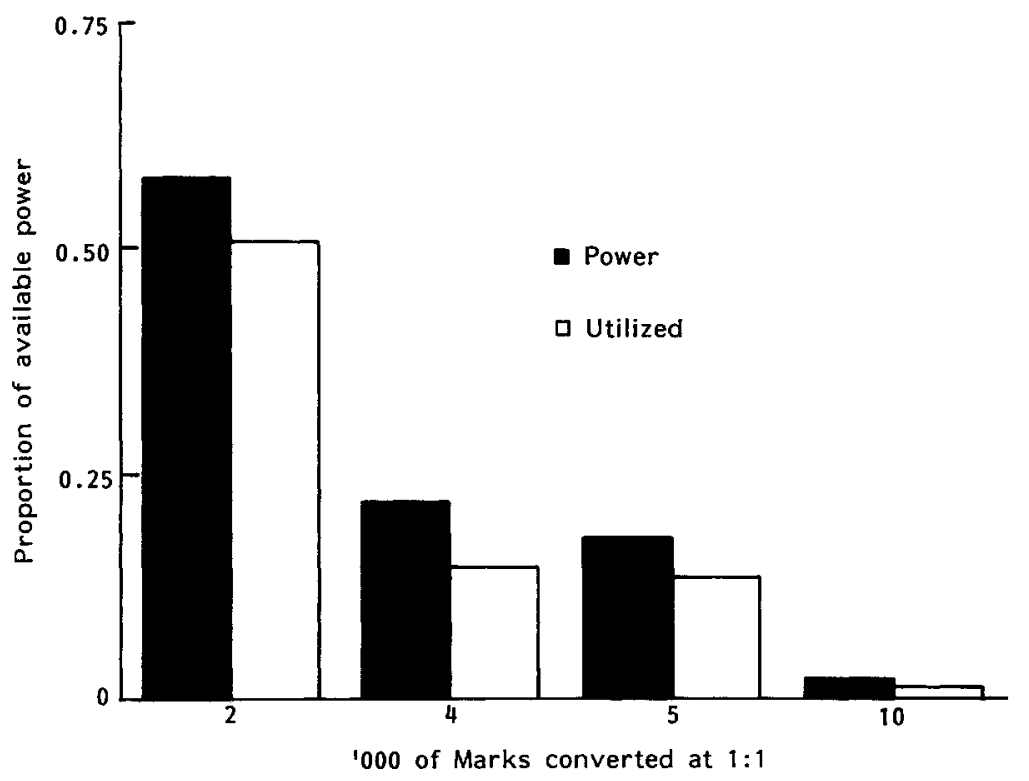

Figure 4. Power and Preferences Regarding Mark Conversion. Kohl's First Move: Shift International Actors.

of the Soviets vis-à-vis the East German CDU) also supports the expectation that the position of the Soviets would shift from 1:1 conversion of all savings to the East German CDU position of 5000 marks, representing their willingness to compromise on their initial demand. Having instituted this comparative static simulation, we find that overwhelming power still supports an outcome of 2000 marks convertible at $1: 1$. Figure 4 shows the new power distribution. Figures $5 a, b$, and $c$ replicate the analysis done earlier, but now we inquire into the perceived relations between Chancellor Kohl and all others under the comparative static simulation that places the United States and the European Community at 4000 marks and the USSR at 5000 marks.

The second comparative static analysis - dictated by the analytic results derived from the first solution of the perceptual model - reveals that a new set of actors would now be willing to make concessions to the CDU, given the initial moves by the United States, Europe, and the USSR. With mounting support for Kohl's 4000 mark proposal, the Greens and the East German communists now appear ready to abandon their support for unlimited conversion and to join the East German CDU and the Soviet Union in accepting the conversion of up to 5000 mark on a one-toone basis. This preparedness to compromise with Kohl can be seen in Figure 5b.

Movement by the Greens and other extreme interests does not alter appreciably the distribution of utilized or potential power, nor does it alter the anticipated outcome. However, the anticipated concessions of these groups fundamentally alter the hardline stance of the West German banks and business interests.

We evaluate the expected impact of the concessions from the Greens and the communists through another comparative statics analysis. Figure 6 shows the distribution of power by preferred outcome if the Greens and the PDS pursued the course of action indicated in Figure 5. Figure 7 shows the impact that their 


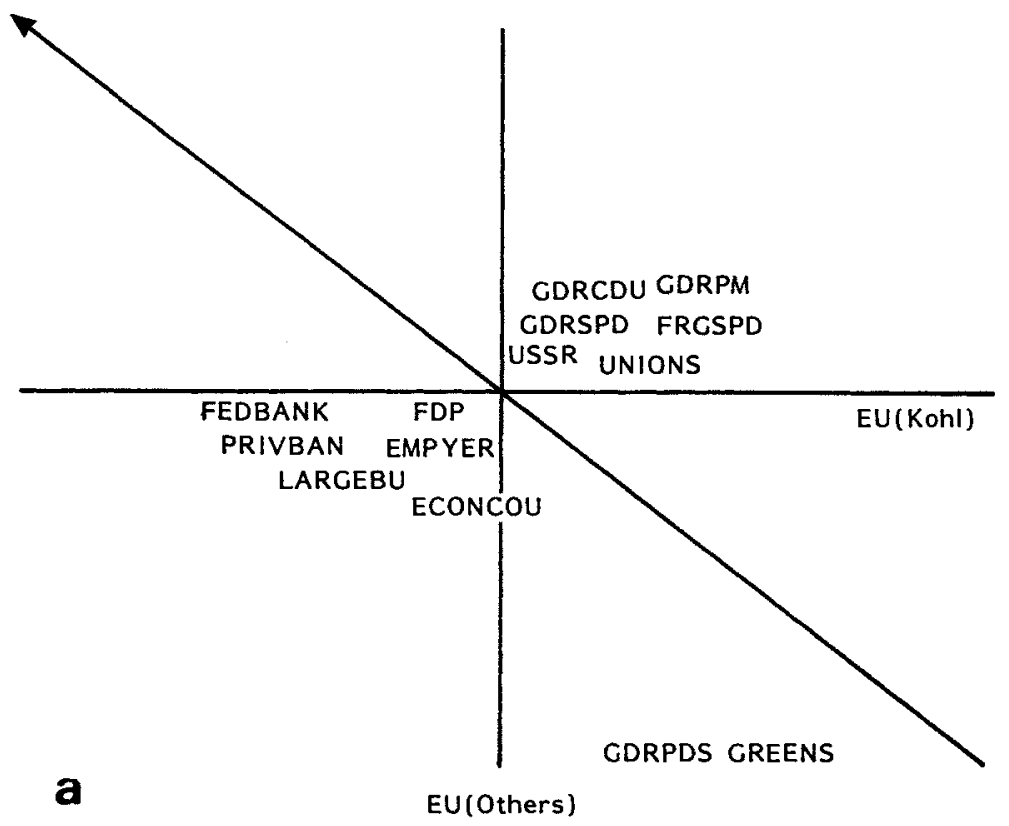

Figure 5a: Comparative Static 1: Kohl's Expectations.

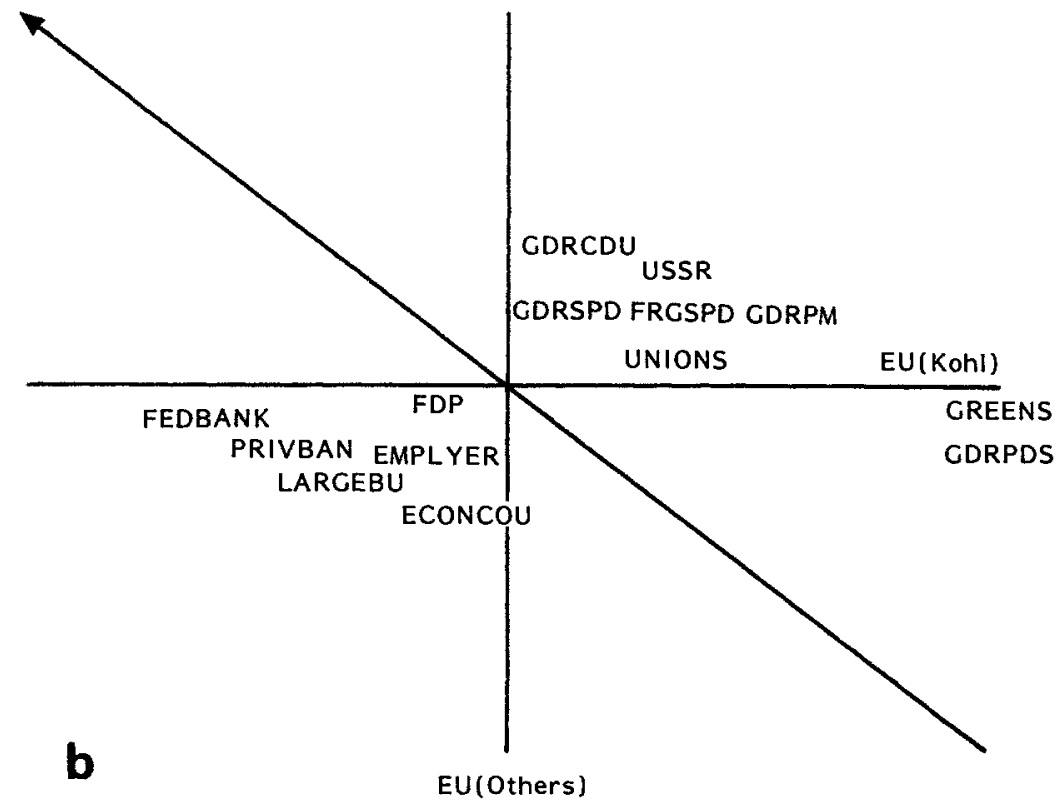

Figure 5b: Comparative Static 1: Others' Expectations. 


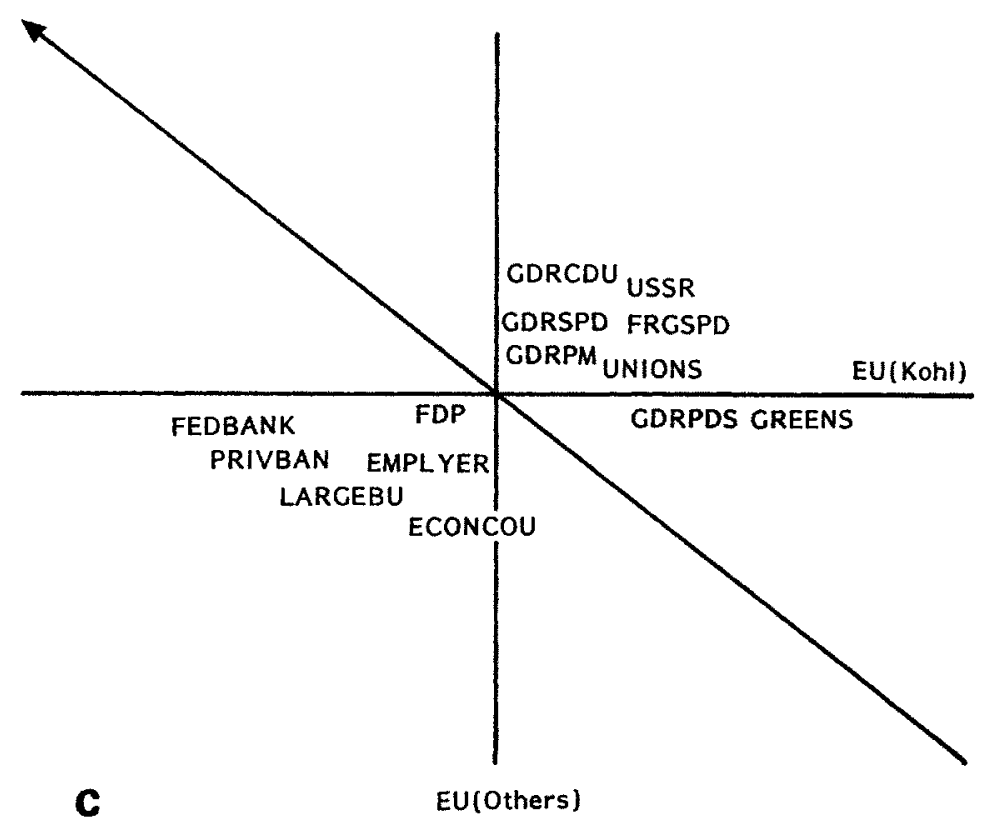

Figure 5c: Comparative Static 1: "Reality" View.

concessions have on the perceptions of the banks and other groups vis-à-vis the West German and the East German GDU.

Apparently, once the extreme left accepts the posture of the CDU, those endorsing a conversion of only 2000 marks at a 1:1 rate are no longer able to sustain their position. Perhaps fearing that their tough stance will jeopardize economic union and will foment a resurgence of extreme leftist interests, the banks and others give in. The model shows that they will accept as much as the conversion of 5000 marks - the position of the East German CDU - despite their predominant power and ability to have enforced a 2000 mark settlement. The forecast outcome in the model indicates a generous settlement largely along the lines initially favored by Chancellor Kohl. The prediction is for an agreement to convert between 4000 and 5000 marks at a one-to-one rate. Figure 8 depicts the changing power distribution from the initial, base case, through each of the comparative static analyses dictated by the model. The final image shows that the majority of power should have been expected gradually to shift to support for a generous settlement for the East Germans.

Of greatest interest in this analysis is the observation that Chancellor Kohl has apparently taken a circumstance in which there was overwhelming support for a harsh agreement and, ad seriatim, persuaded opponents to abandon their position in support of the outcome he favored. He has done this despite the existence of stiff opposition to his proposal at the outset. According to our evaluation, the key to Chancellor Kohl's success is the risk aversion of those who supported a 2000 mark settlement. Despite their overwhelming strength, these groups were defeated by their own fears of the political fallout from a hardline stance. Yet such fallout was unlikely according to the modeling results developed here. The fear that the East Germans would veto a 2000 mark settlement and Kohl's ability to exploit that concern is at 


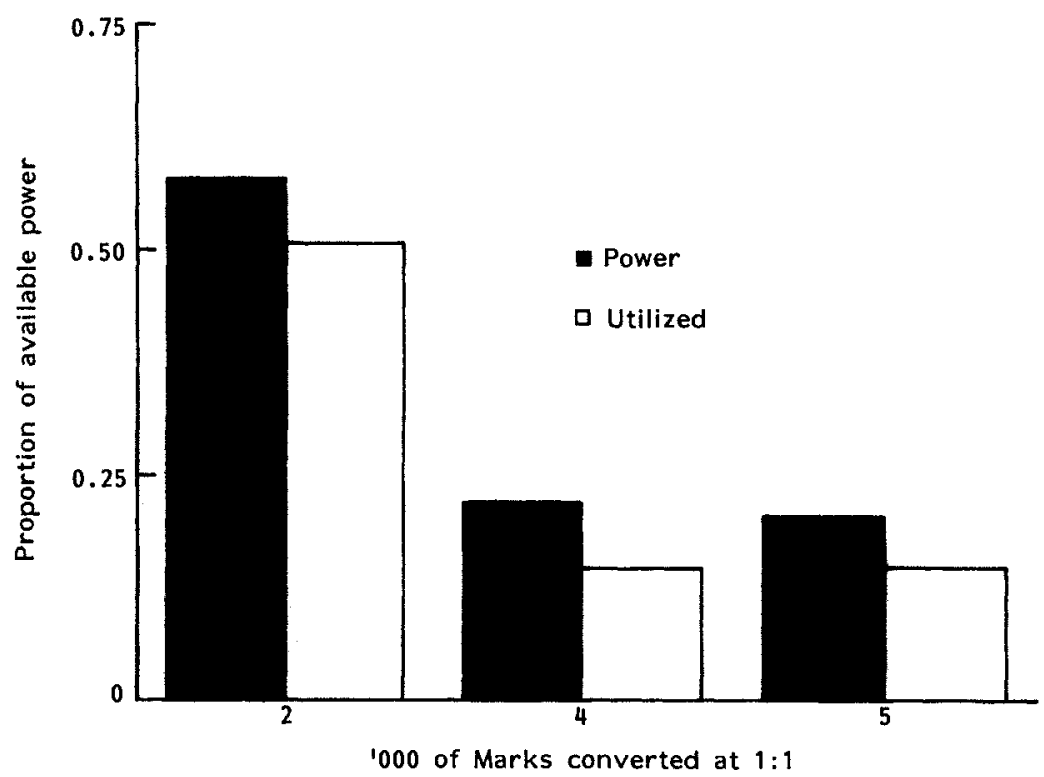

Figure 6. Power and Preferences Regarding Mark Conversion. Kohl's Second Move: Shift Greens and Communist.

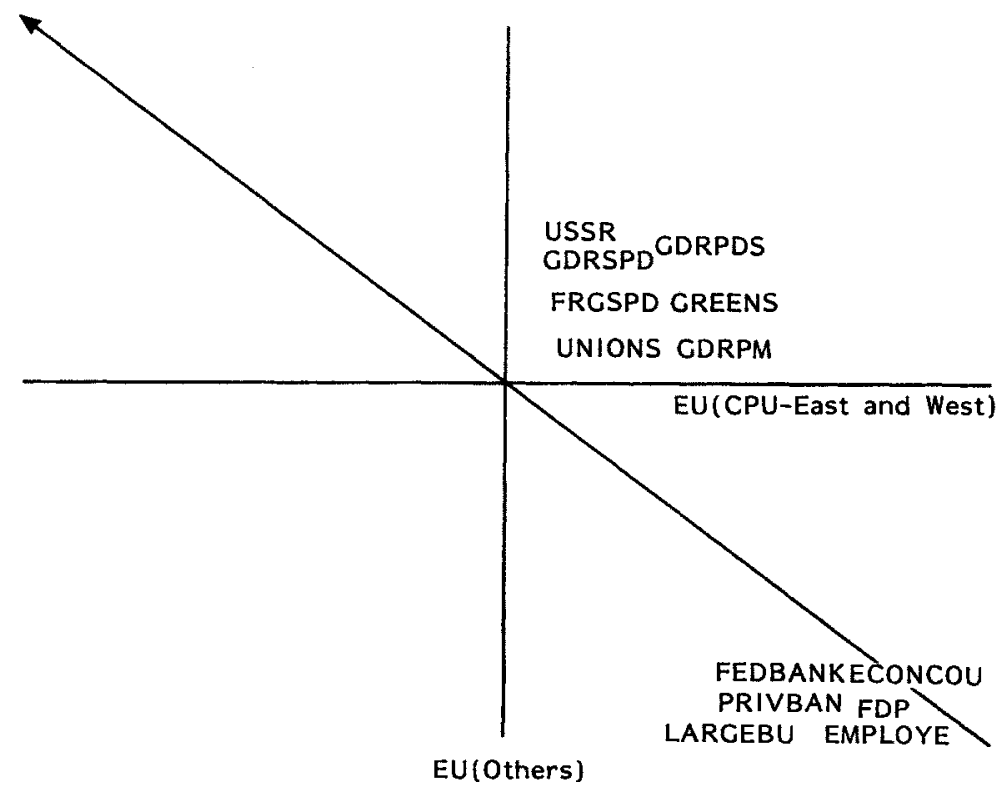

Figure 7. Comparative Static 2: The Banks Capitulate. 


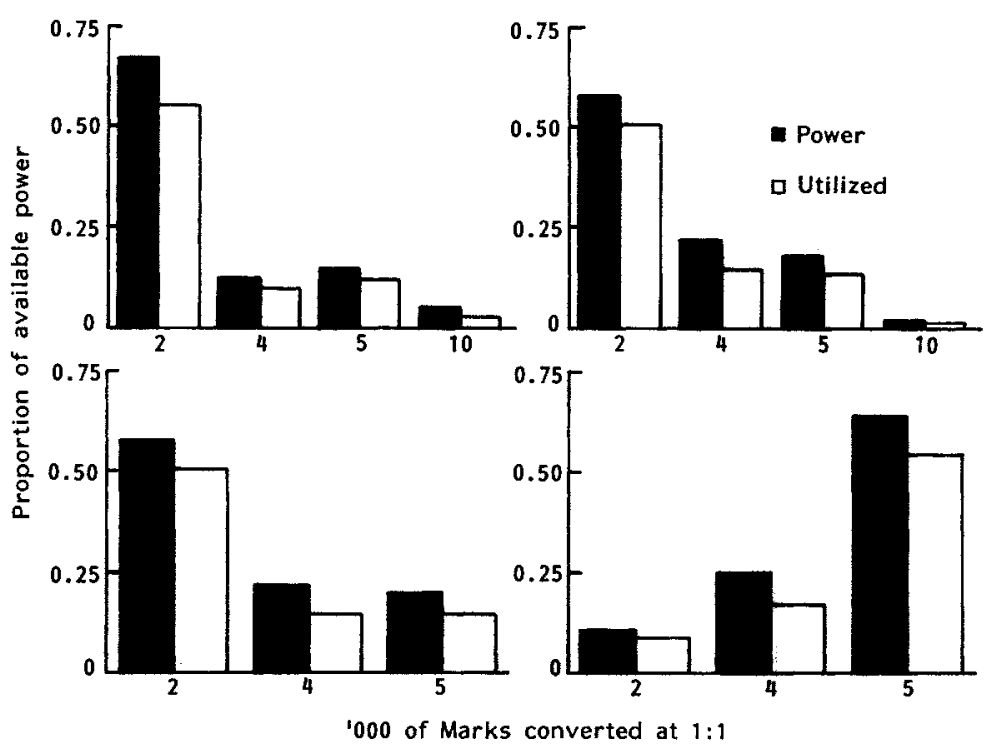

Figure 8. Kohl's Strategy: Conversion of Marks.

the heart of the 4000 mark settlement. And yet our results also show that such concerns were not warranted. The East should have been willing to bluff and posture, but our investigation does not support the belief that they would have walked away from economic union if they had only gotten an agreement to convert 2000 marks on a one-to-one basis.

\section{Conclusion}

We have delineated a model for forecasting policy outcomes and political perceptions. The model has been applied to the economic integration of the two Germanys. It shows that through a series of subtle political maneuvers it was possible for Chancellor Kohl to defeat those who wished to impose a harsh (perhaps realistically harsh) economic arrangement on the East Germans. Kohl was able to do so despite the fact that nearly 70 percent of all the potential political influence focused on this question was initially controlled by those who wanted an exchange of 2000 marks only on a 1:1 basis. Perceptions proved to be the key. At each step along the path to an agreement, Kohl apparently capitalized on the beliefs of his opponents that they needed to make concessions to his wishes. Through the application of a model of rational expectations we have seen how beliefs and perceptions could be exploited to structure a settlement that deviates markedly from the initial median voter outcome.

\section{Notes}

1. A Condorcet winner is any alternative that in head to head competition defeats each other alternative.

2. For applications to settings that do not involve conventional voting see Bueno de Mesquita, 1984, 1990a; Bueno de Mesquita, Newman, and Rabushka, 1985; Morrow, 1986; Morgan, 1984,1989 , and 1990. 
3. Later we suggest an estimation procedure for specifying the function.

4. The model here is not game theoretic. It does, however, contain a rational expectations component that looks at anticipated courses of action in the event a group does not challenge a policy proposal. Decision theoretic models with such components tend to converge on game theoretic equilibria. See Marcet and Sargent, November 1987, December 1987.

5. The measurement of the probability of success for $i$ 's preferred outcome in a competition with $j$ 's preferred outcome is accomplished using the following specification:

$$
P_{i}\left[X_{i}(m) \mid X_{j}(m)\right]=\frac{\sum_{k i p j} V_{k} \text { given }\left[X_{i}(m), X_{j}(m)\right]}{\sum_{k=1}^{n} \mid V_{k} \text { given }\left[X_{i}(m), X_{j}(m)\right] \mid}
$$

with " $p$ " denoting preference and with utilities (U terms) and salience (S terms) in $V_{k}$ defined as described in Bueno de Mesquita, Newman, and Rabushka (1985).

6. For a detailed example (drawn from Italian politics) of such an application of the model, see Beck and Bueno de Mesquita, 1985.

7. The data for this study were collected in April 1990 and the analysis was completed in the same month, before the announcement of the actual agreement by which the currencies were merged. Consequently, we continue to use language implying a future event although at the time of publication, of course, the issue has long been settled.

\section{References}

Banks, J. (1990). "Equilibrium Behavior in Crisis Bargaining Games." American Journal of Political Science 34: 599-614.

Beck, D. and B. Bueno de Mesquita (1985). "Forecasting Policy Decisions: An Expected Utility Approach." In Corporate Crisis Management (S. Andriole, ed.) Princeton, NJ: Petrocelli Books.

Black, D. (1958). Theory of Committees and Elections. Cambridge: Cambridge University Press.

Bueno de Mesquita, B. (1984). "Forecasting Policy Decisions: An Expected Utility Approach to Post-Khomeini Iran." PS 17: 226-236.

Bueno de Mesquita, B. (1985). "The War Trap Revisited." American Political Science Review 79: 157-176.

Bueno de Mesquita, B. (1990a). "Multilateral Negotiations: A Spatial Analysis of the ArabIsraeli Dispute." International Organization 44: 317-340.

Bueno de Mesquita, B. (1990b). "Pride of Place: The Origins of German Hegemony." World Politics 43: 28-52.

Bueno de Mesquita, B. and D. Lalman (1986). "Reason and War." American Political Science Review. 80: 1113-1131.

Bueno de Mesquitta, B., D. Newman and A. Rabushka (1985). Forecasting Political Events: The Future of Hong Kong. New Haven, CT: Yale University Press.

Davis, O., M. DeGroot, and M. Hinich (1974). "Social Preference Orderings and Majority Rule." Econometrica 40: 147-157.

Dean, J. (1989). "The Changing Security Dimension of the Inter-German Relationship." In The Two German States and European Security (F.S. Larrabee, ed.) New York: St. Martin's Press.

Downs, A. (1957). An Economic Theory of Democracy. New York: Harper and Row.

Kaser, M. (1989). "The Economic Dimension." In The Two German States and European Security (F.S. Larrabee, ed.) New York: St. Martin's Press.

Kramer, G. (1972). "Sophisticated Voting over Multidimensional Choice Spaces." Journal of Mathematical Sociology 2:165-180.

Lalman, D. (1988). "Conflict Resolution and Peace." American Journal of Political Science 32: $590-615$.

Marcet, A. and T. Sargent (1987). "The Fate of Systems with 'Adaptive Expectations'." Stanford, GA.: Hoover Institution, November. 
Marcet, A. and T. Sargent (1987). "Convergence of Least Squares Learning in Environments with Hidden State Variables and Private Information." Stanford, CA.: Hoover Institution, December.

McKelvey, R. (1976). "Intransitivities in Multidimensional Voting Models and Some Implications for Agenda Control." Journal of Economic Theory 16: 472-482.

Morgan, T.C. (1984). “A Spatial Model of Grisis Bargaining." International Studies Quarterly 28: 407-426.

Morgan, T.C. (1989). "Power, Resolve and Bargaining in International Crises: A Spatial Theory." International Interactions 15: 289-312.

Morgan, T.G. (1990). "Issue Linkages in International Crisis Bargaining." American Journal of Political Science 34: 311-333

Morrow, J.D. (1986). "A Spatial Model of International Conflict." American Political Science Review 80: 1131-1150.

Morrow, J.D. (1987). "On the Theoretical Basis of a Measure of National Risk Attitudes." International Studies Quarterly 31: 423-438.

Organski, A.F.K. and J. Kugler (1980). The War Ledger. Chicago: University of Chicago Press. Schofield, N. (1976). "Instability of Simple Dynamic Games." Review of Economic Studies 45: 575-594.

Schweigler, G. (1989). "German Questions or the Shrinking of Germany." In The Two German States and European Security (F.S. Larrabee, ed.) New York: St. Martin's Press.

\section{Biographical Notes}

Bruce Bueno de Mesquita is a Senior Fellow at the Hoover Institution, Stanford University, and Professor of Political Science at the University of Rochester. His most recent book, War and Reason (with David Lalman), is scheduled for publication by Yale University Press in 1992. ADDREss: Hoover Institution, Stanford, CA, 94305, USA.

A.F.K. Organski is a Professor of Political Science, and Program Direcctor of the Center for Political Studies, at the University of Michigan. His latest book, The ThirtySix Billion Dollar Bargain, was published by Columbia University Press in 1990. ADDREsS: Department of Political Science, University of Michigan, Ann Arbor, MI 48104, USA.

Acknowledgments. We are very grateful to Professor Donald Hancock of Vanderbilt University for providing the data required for this study and for his patience with us. We also appreciate the assistance of Jacek Kugler and Ellen Lust. An earlier version of this paper was prepared with support from the American-Dutch Conference in Groningen, The Netherlands. We thank our colleagues at Groningen, and especially Frans Stokman, for their support and encouragement. 